\title{
Histidine Suppresses Zinc Modulation of Connexin Hemichannels
}

\author{
RICHARD L. CHAPPELL ${ }^{1,2, *}$, HAOHUA QIAN ${ }^{1,3}$, JANE ZAKEVICIUS ${ }^{1,3}$, \\ AND HARRIS RIPPS ${ }^{1,3}$ \\ ${ }^{1}$ Marine Biological Laboratory, Woods Hole, Massachusetts; ${ }^{2}$ Hunter College and The Graduate \\ Center, CUNY, New York, New York; and ${ }^{3}$ University of Illinois at Chicago, College of Medicine, \\ Chicago, Illinois
}

Zinc has been shown to modulate hemichannel currents of connexins Cx35 and Cx38 in Xenopus oocytes (1). In both cases the effects were biphasic; i.e., low concentrations of zinc enhanced, whereas higher concentrations decreased, the magnitudes of the voltage-activated hemichannel currents. The present study was designed to determine the effects of zinc on hemichannels formed by Cx26, a connexin reportedly expressed on dendrites of carp horizontal cells and implicated in a mechanism for photoreceptor feedback (2, 3, 4). In addition, we examined whether histidine, a zinc chelator, would block the action of zinc on Cx26 hemichannel currents, or would exert a direct effect on those currents.

Methods for oocyte preparation and recording of connexin hemichannel currents followed procedures described previously (5). Briefly, Stage V-VI oocytes were removed from gravid female Xenopus, enzymatically dissociated and defolliculated, and then used to express human Cx26 connexin in the presence of an antisense oligomer to the endogenous oocyte connexin (Cx38). The oocytes were maintained in modified Barth's solution (MB) that contained [in $\mathrm{mM}$ ]: $\mathrm{NaCl}$ [88], $\mathrm{KCl}$ [1], $\mathrm{NaHCO}_{3}$ [2,3], $N$-2-hydroxyethylpiperazine- $N^{\prime}$-2-ethanesulfonic acid (HEPES) [15], $\left.\mathrm{Ca}\left(\mathrm{NO}_{3}\right)_{2}\right)$ [0.33], $\mathrm{CaCl}_{2}$ [0.41], and $\mathrm{MgSO}_{4}$ [0.82]; $\mathrm{pH}$ 7.6. Voltage-activated membrane currents were recorded with a two-electrode voltage clamp. The two protocols we used gave equivalent results: (1) with the cell clamped at $0 \mathrm{mV}$, 10 -s voltage steps were imposed from $-50 \mathrm{mV}$ to $+50 \mathrm{mV}$ in $10-\mathrm{mV}$ increments, and (2) from the holding potential of

Received 1 September 2004; accepted 7 October 2004.

* To whom correspondence should be addressed at Hunter College Biology Department, 695 Park Avenue, New York, NY 10021. E-mail rchappell@gc.cuny.edu
$0 \mathrm{mV}$, currents were recorded in response to voltage ramps extending from $-100 \mathrm{mV}$ to $+60 \mathrm{mV}$ at a rate of 0.04 $\mathrm{mV} / \mathrm{ms}$.

Figure 1 compares a representative record from an oocyte expressing Cx26 with those obtained from an antisenseinjected cell and one that was not injected but expressed Cx38, its endogenous connexin. Note the efficacy with which the antisense oligo suppressed the current mediated by $\mathrm{Cx} 38$, and the significantly greater membrane currents of Cx26 in response to both depolarizing and hyperpolarizing voltages.

Figure 2A shows current recordings from oocytes expressing human $\mathrm{Cx} 26$ in $\mathrm{MB}$ and after the addition of various concentrations of zinc. In $\mathrm{MB}$, a voltage ramp from $-100 \mathrm{mV}$ to $+60 \mathrm{mV}$ elicited large currents at all potentials positive and negative to the reversal potential $(-10 \mathrm{mV})$, suggesting that the hemichannels are constitutively open (5). In the presence of low $(1 \mu M)$ concentrations of zinc, the magnitude of the currents through $\mathrm{Cx} 26$ hemichannels was substantially enhanced. Higher concentrations of zinc, however, decreased these currents in a dose-dependendant fashion such that $10 \mu M$ zinc reduced the hemichannel currents to the level seen in control MB solution, and 100 $\mu M$ and $1 \mathrm{~m} M$ zinc further decreased the hemichannel currents. The bar graphs of Figure 2B, taken from the data in Figure 2A, illustrate the effects of zinc on Cx26 hemichannel currents recorded at $+40 \mathrm{mV}$. Both the enhancement and inhibition by zinc of the $\mathrm{Cx} 26$ hemichannel current showed little voltage dependence. As shown in Figure $2 \mathrm{C}$, the ratio of the membrane currents measured in zinc to those recorded in $\mathrm{MB}$ were virtually unchanged across the range of membrane voltage tested (from -100 $\mathrm{mV}$ to $+60 \mathrm{mV})$ for both low concentrations $(1 \mu M)$ and 


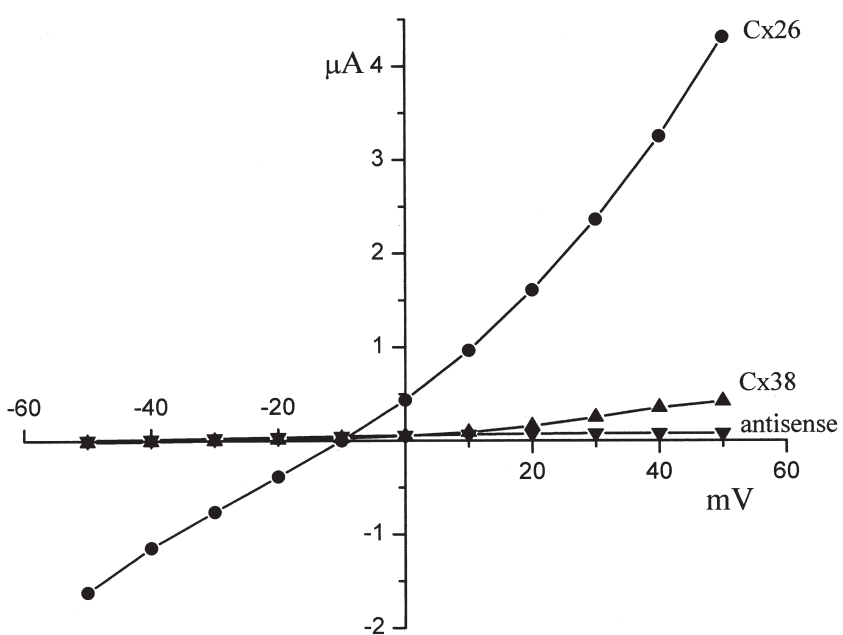

Figure 1. The I-V curves resulting from recordings of the nonjunctional membrane currents of Xenopus oocytes expressing Cx26, the endogenous $\mathrm{Cx} 38$, or an antisense oligomer to nucleotides within the coding region of $\mathrm{Cx} 38$.

high concentrations $(100 \mu M)$ of zinc. However, recovery of Cx26 hemichannel currents following application of 1 $\mathrm{m} M$ zinc was extremely slow, requiring more than $15 \mathrm{~min}$ for the current to return to control level after the zinc was removed (Fig. 2D).

We found that $1 \mathrm{~m} M$ histidine, a zinc chelator, com-
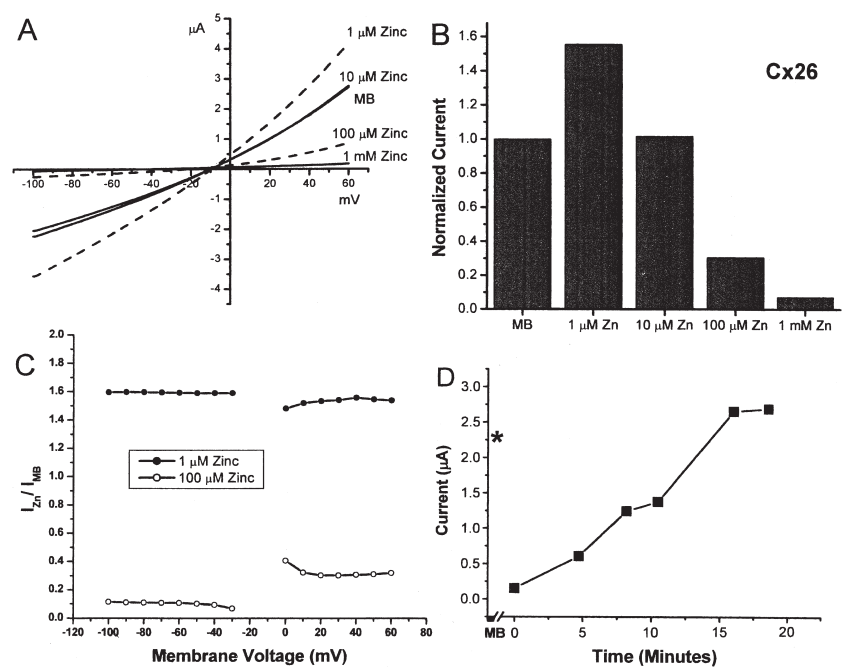

Figure 2. Zinc modulates hemichannels formed by $\mathrm{Cx} 26$ connexins expressed in Xenopus oocytes. (A) Voltage ramp recordings show greater current responses in $1 \mu M$ zinc than in control (MB) solution. The effect is biphasic, such that with higher concentrations, the currents are progressively suppressed in a dose-dependant fashion. (B) Dose-response relation for $\mathrm{C} \times 26$ hemichannel currents measured at $+40 \mathrm{mV}$ during the voltage ramp from $-100 \mathrm{mV}$ to $+60 \mathrm{mV}$. (C) Ratios of membrane currents measured in zinc to those measured in $\mathrm{MB}\left(I_{\mathrm{Zn}} / I_{\mathrm{MB}}\right)$ are not a function of clamp voltage. (D) Current recovery following the application of $1 \mathrm{mM}$ zinc was very slow, taking almost $15 \mathrm{~min}$ for full recovery to control levels (asterisk); the currents plotted here were measured at $+50 \mathrm{mV}$.
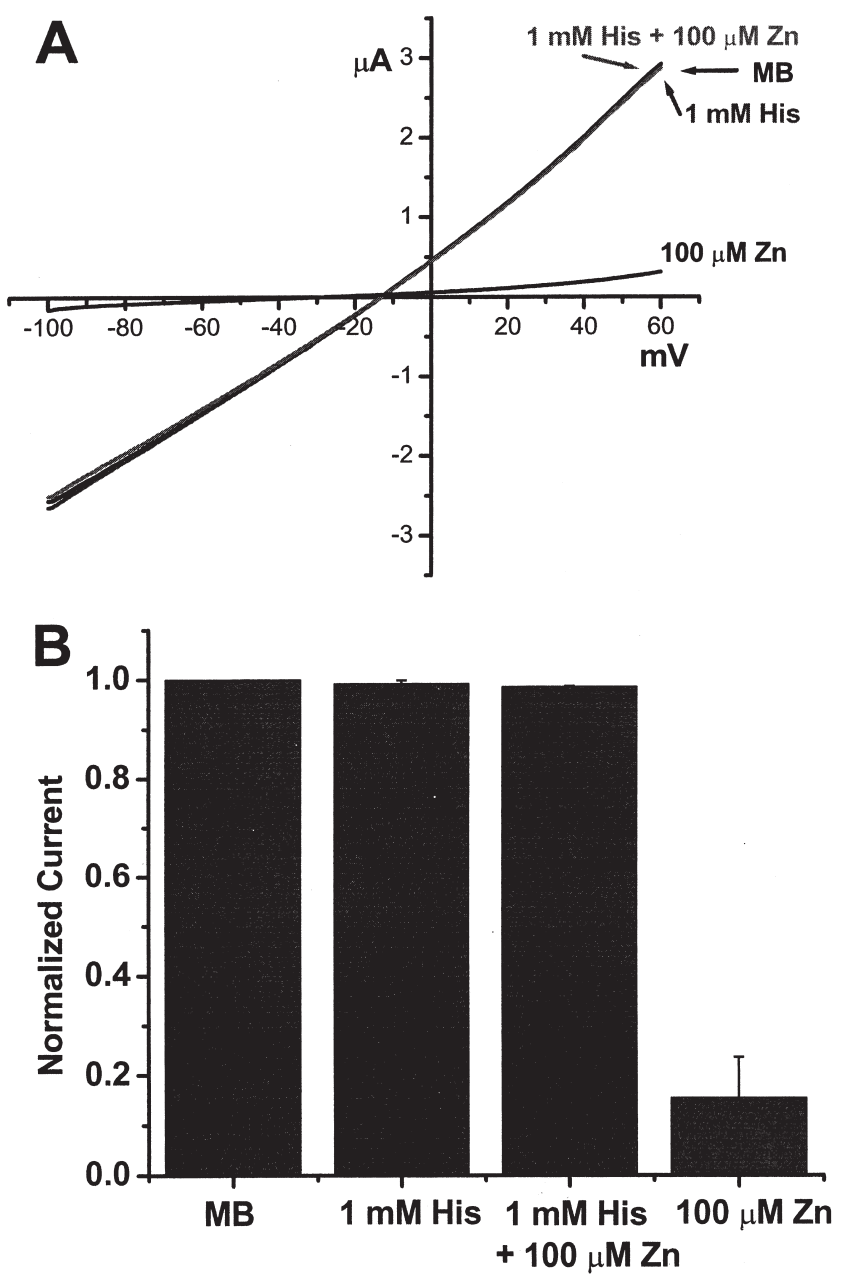

Figure 3. Histidine has no direct effect on Cx26 hemichannels. (A) $100 \mu M$ zinc, which had a profound effect on Cx26 hemichannel membrane currents, was completely ineffective in the presence of $1 \mathrm{mM}$ histidine (His). When compared with currents elicited in the control MB solution, $1 \mathrm{~m} M$ histidine alone had no effect on the $\mathrm{Cx} 26$ hemichannel currents elicited by a voltage ramp from -100 to $+60 \mathrm{mV}$. (B) Bar graphs showing normalized currents, recorded at $+40 \mathrm{mV}$, for the four experimental conditions; error bars $= \pm$ S.E.M., $n=5$.

pletely blocked the inhibitory effects of $100 \mu M$ zinc on Cx26 hemichannel currents. In the presence of $1 \mathrm{~m} M$ histidine, the voltage-activated currents obtained in $100 \mu M$ zinc were almost identical to those recorded in MB (Fig. $3 \mathrm{~A})$. In addition, we showed that $1 \mathrm{~m} M$ histidine alone had no direct effect on hemichannel currents. Averaged values from five cells exposed to the various experimental conditions are shown in Figure 3B.

The possible roles of hemichannels in the retina and elsewhere in the nervous system remain controversial. However, there is both histological and physiological evidence that $\mathrm{Cx} 26$ hemichannels on the horizontal cell dendrites that invaginate carp photoreceptor terminals participate in a feedback mechanism that regulates calcium entry and thereby affects transmitter release (3). Although similar 
findings have been reported in turtle retina (4), studies of mouse retina suggest that murine horizontal cells lack Cx26 (6), and express Cx57 (7). Nevertheless, a study of horizontal cell-photoreceptor feedback in mouse retina using the hemichannel blocker carbenoxolone yielded data that were consistent with a model in which hemichannels modulate cone transmitter release by effectively opening more $\mathrm{Ca}^{2+}$ channels (8). In contrast, carbenoxolone was recently reported to reduce the amplitude of $\mathrm{Ca}^{2+}$ channel currents in isolated salamander cones, suggesting that carbenoxolone could be inhibiting $\mathrm{Ca}^{2+}$ channels directly (9).

The results reported here and in earlier studies on the zinc sensitivity of hemichannel currents led us to consider the zinc effects in the context of the hemichannel feedback mechanism of Kamermans et al. (3). In this connection, it is important to recall the pioneering study of Wu et al. (10), who showed histochemically the presence of a relatively high concentration of reactive zinc in the region of the photoreceptor terminals in salamander retina, and the fact that similar findings were obtained in the retinas of skate (11) and rat (12). The colocalization of zinc with glutamate in the photoreceptor terminals, and the results of electrophysiological experiments showing that zinc suppressed glutamate release by reducing calcium entry into the terminals (10), led the authors to suggest that zinc may serve as a gain-control mechanism at the first synapse of the visual system. Although the possibility remains that zinc exerts a direct effect on calcium channels, its effect on transmitter release may derive from its ability to modulate the hemichannel currents on horizontal cells at the photoreceptor synapse. On this view, raising the extracellular concentration of zinc $(>10 \mu M)$ to suppress $\mathrm{Cx} 26$ hemichannel currents would be expected to reduce calcium entry in the photoreceptor terminals and thus reduce the release of its neurotransmitter, glutamate.

The present findings may have a direct bearing on the results of recent studies showing that 100-500 $\mu M$ histidine significantly enhances the electroretinographic b-wave responses in the dark-adapted retinas of both skate and zebrafish $(13,14,15)$. Glutamate release and, presumably, the co-release of zinc are maximal in darkness, and their rapid reduction by a light flash elicits a voltage response in second-order neurons that is proportional to the magnitude of the decrease in neurotransmitter. If zinc reduces the calcium-regulated release of glutamate through its action on hemichannels, its chelation by histidine would enhance glutamate release and produce the observed increase in the b-wave potential generated by second-order cells. Thus, if zinc is co-released with glutamate, as has been shown for some glutamatergic hippocampal cells (16), the presence of zinc within the photoreceptor synapse may serve to establish the basal level of transmitter release.

\section{Acknowledgments}

This work was supported in part by Fight for Sight, PSC/CUNY Grant 66257-0035, and NCRR/NIH RCMI Award RR-03037 (RLC); NIH Grants EY-06516 (HR), EY-14557 (HR), EY-12028 (HQ); and a Senior Research Investigator Award from Research to Prevent Blindness (HR).

\section{Literature Cited}

1. Chappell, R. L., J. Zakevicius, and H. Ripps. 2003. Zinc modulation of hemichannel currents in Xenopus oocytes. Biol. Bull. 205: 209-211.

2. Janssen-Bienhold, U., K. Schultz, A. Gellhaus, P. Schmidt, J. Ammermüller, and R. Weiler. 2001. Identification and localization of connexin26 within the photoreceptor-horizontal synaptic complex. Vis. Neurosci. 18: 169-178.

3. Kamermans, M., I. Fahrenfort, K. Schultz, U. Janssen-Bienhold, T. Sjoerdsma, and R. Weiler. 2001. Hemichannel-mediated inhibition in the outer retina. Science 292: 1178-1180.

4. Pottek, M., W. Hoppenstedt, U. Janssen-Bienhold, K. Schultz, I. Perlman, and R. Weiler. 2003. Contribution of connexin26 to electrical feedback inhibition in the turtle retina. J. Comp. Neurol. 466: $468-477$.

5. Ripps, H., H. Qian, and J. Zakevicius. 2004. Properties of connexin26 hemichannels expressed in Xenopus oocytes. Cell. Mol. Neurobiol. 24: 647-665.

6. Deans, M. R., and D. L. Paul. 2001. Mouse horizontal cells do not express connexin26 or connexin36. Cell Commun. Adhes. 8: 361-366.

7. Hombach, S., U. Janssen-Bienhold, G. Sohl, T. Schubert, H. Bussow, T. Ott, R. Weiler, and K. Willecke. 2004. Functional expression of connexin57 in horizontal cells of the mouse retina. Eur. J. Neurosci. 19: 2633-2640.

8. Xia, Y., and S. Nawy. 2003. The gap junction blockers carbenoxolone and $18 \beta$-glycerretinic acid antagonize cone-driven light responses in the mouse retina. Vis. Neurosci. 20: 429-435.

9. Vessey, J. P., M. R. Lalonde, H. A. Mizan, N. C. Welch, M. E. M. Kelly, and S. Barnes. 2004. Carbenoxolone inhibition of voltagegated $\mathrm{Ca}$ channels and synaptic transmission in the retina. J. Neurophysiol. 92: 1252-1256.

10. Wu, S. M., X. Qiao, J. L. Nobels, and X. L. Yang. 1993. Localization and modulatory actions of zinc in vertebrate retina. Vision Res. 33: $2611-2616$

11. Qian, H., L. Li, R. L. Chappell, and H. Ripps. 1997. GABA receptors of bipolar cells from the skate retina: actions of zinc on GABA-mediated membrane currents. J Neurophysiol. 78: 2402-2412.

12. Ugarte, M., and N. N. Osborne. 1999. The localization of free zinc varies in rat photoreceptors during light and dark adaptation. Exp. Eye Res. 69: 459-461.

13. Rosenstein, F. J., and R. L. Chappell. 2003. Endogenous zinc as a retinal neuromodulator: evidence from the skate (Raja erinacea). Neurosci. Lett. 345: 81-84.

14. Redenti, S., and R. L. Chappell. 2003. Zinc chelation enhances the sensitivity of the ERG b-wave in dark-adapted skate retina. Biol. Bull. 205: 213-214.

15. Redenti, S., and R. L. Chappell. 2002. Zinc chelation enhances the zebrafish retinal ERG b-wave. Biol. Bull. 203: 200-202.

16. Frederickson, C. J., and D. W. Moncrieff. 1994. Zinc-containing neurons. Biol. Signals 3: 127-139. 